DOI: $\underline{10.20472 / S S .2017 .6 .2 .004 ~}$

\title{
A PATTERN ANALYSIS APPLICATION: TIME SERIES TRACES OF THE EFFECT OF KAMRAN KHAVARANI'S PAINTINGS ON VIEWERS' MOOD
}

\author{
SIMIN MOZAYENI, KARL HEINER, PARISA AMIRMOSTOFIAN
}

\begin{abstract}
:
We apply a Pattern Analysis to evaluate the "lasting aesthetic effect" of Kamran Khavarani's paintings on viewers' mood. Our sample encompasses 252 subjects. All subjects visited three galleries, one of which was Khavarani's, albeit in different orders. The data include the subjects' moods before and after visits, the order of their visits and their genders and age brackets. Almost every subject in the group who visited Khavarani's gallery first, experienced an increase in their "mood" that eventually declined after leaving that gallery. We have considered 64 combinations of patterns emerging from our data and conducted all respective regressions. The Chi Squares $(\chi 2)$ in all cases lead to accepting the null hypothesis for independence of the variables, with high $P$ values. We confirm that Khavarani's painting style has a "lasting" effect on viewer's mood.
\end{abstract}

\section{Keywords:}

A Pattern Analysis of Lasting Effect of Paintings; Time Series Traces of Aesthetic Effect of Paintings; Time Series Traces of Kamran Khavarani's Paintings on Viewers' Mood; Lasting Aesthetic Effect of Khavarani's Painting; Lasting Aesthetic Effect of "Abstract Romanticism"; Pattern Analysis in Aesthetic Research; Statistical Modeling

JEL Classification: C90, Z10

\section{Authors:}

SIMIN MOZAYENI , State University of New York at New Paltzt, United States, Email: mozayens@newpaltz.edu KARL HEINER , SUNY New Paltz, United States, Email: kwheiner@aol.com PARISA AMIRMOSTOFIAN , NA, United States, Email: parisa@parisaarttherapy.com

\section{Citation:}

SIMIN MOZAYENI , KARL HEINER, PARISA AMIRMOSTOFIAN (2017). A Pattern Analysis Application: Time Series Traces of the Effect of Kamran Khavarani's Paintings on Viewers' Mood . International Journal of Social Sciences, Vol. VI(2), pp. 44-62., 10.20472/SS.2017.6.2.004 


\section{Introduction}

Our research goal is to investigate the "lasting effect" of Khavarani's painting style, known as "Abstract Romanticism," on viewer's mood. We use a Pattern Analysis methodology to conduct our investigation. To the best of our knowledge, application of Pattern Analysis is an innovative approach in the Aesthetic modeling. Also, this research is the first study in the literature that examines the "lasting" effect of paintings. Third, this study is the first in the literature that specifically examines the "lasting effect" of the Khavarani's style of painting, known as "Abstract Romanticism," a new genre of painting, which was discovered by Albert Boime (2008). Lastly, this research complements our two static studies of the effect of Khavarani's paintings on viewer's mind.

In Amirmostofian and Mozayeni (2016), we used nonparametric models of Freidman, Mann-Whitney and Kruskal-Wallis. In Mozayeni and Amirmostofian (2016), we considered the regression results for the parametric Multivariate General Linear Model (MGLM), in 12 specifications and assessed the effect of Khavarani's paintings on subject's mind. With the latter specification, we extracted more information from our data, pertaining to subject's base mood, age group and gender. We examined those variables' collective effect on subject's "mood" after viewing paintings in the experimental gallery and the other two in our sample. Based on both nonparametric and parametric model specifications, we confirmed the a priori hypothesis that Khavarani's paintings have positive effect on viewers' psyche. Here we extend those investigations beyond the static modeling and consider the time series traces of the effect of Khavarani's paintings on viewer's mind.

Since this research is an extension of Mozayeni and Amirmostofian (2016), et al., and Amirmostofian and Mozayeni (2016), et al., we draw our core data from those studies. Also, our literature reviews are nearly the same.

Combination of our statics analyses, Amirmostofian and Mozayeni (2016) and Mozayeni and Amirmostofian (2016), et al. and the pattern analysis of Khavarani's paintings, we contribute to the Aesthetics literature in a unique way.

We foresee a potential application of our research in enhancement of the physical environment of public places such as hospitals, clinics, dental offices and hospices, among others. The presence of artworks in hospitals is traced back to the $14^{\text {th }}$ century. And as Staricoff (2006) notes the European Charter on Environment and Health has declared that aesthetics factor, among several other environmental factors, effect health and wellbeing. We plan to expand our quantitative research in that direction and investigate the economic benefits of installation of the artworks that boost viewers' mood in healthcare facilities.

In the following three sections, we present the review of the aesthetic literature related to our research; our data, methodology, the emerging patterns from our data and the regressions' results; followed by a summary of our findings and conclusions.

\section{Literature Review}

The importance of the effect of visual arts on the human brain has been for long the subject of inquiries in psychobiology, social psychology, neurology, and more recently in 
neurasthenics. Numerous studies have examined the aesthetic effects of color, shape and lighting in space design on the human psyche. Several have specifically evaluated the effect of paintings on the human brain.

We reiterate that the literature review here is mostly as we have presented in Amirmostofian and Mozayeni (2016) and Mozayeni and Amirmostofian (2016). Accordingly, we note that the related literature generally falls on two distinct tracks, namely, theoretical or empirical. A few have formulated their empirical observations to develop the theory of beauty and aesthetics. Irrespective of their focus and methodology, they amass strong evidence that visual arts stimulate the brain and affect viewers' psyche, and thus their mood. We review both the theoretical and empirical aesthetic literature, which have mostly emerged in the last 10 years, almost in parallel. Although, the advent of fMRI technology has facilitated direct observation of the effect of art stimuli on the human brain, the survey method has eased the research administratively and economically. According to the joint study by Johns Hopkins' Brain and Mind Center and the Walter Museum, noted in Vikan (2010), these two methods produce "identical" results. Their finding unifies the two method of empirical research.

The old and new notable theoretical works in aesthetics include: Tolstoi (1897-98], Berlyne (1965, 1971 and 1974), Ramachandran and Hirtstein (1999), Zeki (1999), Solso (2003), Reber and Schawarz (2004), Silvia (2005), Anjan and Vartanian (2011), Ishuzi and Zeki (2011), Gopnikc (2012), Hager and associates (2012), Kendal (2012), Vartanian and Skov (2014), among others.

Major empirical works in aesthetics over the last decade include: Cela-Conde (2004), Kemp and Cupchick [2007], Silvia [2007], a joint study by the Johns Hopkins Brain and Mind Center with Walter Museum (2010), Lacey and associates (2011), Tsuklura and Gabeza (2011), Zeki (2011), Vessel (2013), and Vartanian and Skov (2014), and Amirmostofian and Mozayeni, et al, (2016).

The common theme that emerges from these works clearly point to evidence that the human brain responds to certain characteristics in visual arts, being beauty or ugliness. In that way, arts affect the human life. Berlyne (1971) noted that art has always been an instrument for beatifying life in all 3,000 cultures of the world. He thus suggested that the value of art must be measured by its effect on human life. He unequivocally submitted: "...effectiveness of a work of art invariably hinges quite subtly on how much a certain quality is present." (p. 5). For measurement of such effect, he proposed a five-point maxim for judging the quality of art. (p. 61), which has provoked many more such inquiries in the field.

Berlyne in a different work (1974) noted that work of art is analyzed in informationtheoretical terms, as collection of all its elements, each of which can transmit information from four distinct sources: Semantic Information, Expressive Information, Cultural Information and Syntactic Information; together they define the characteristics and the elements of a work of art. (p. 9). Closely related, he noted, are: (1) Characteristics of an external object, (2) psychological process within the artist, (3) social norm and (4) characteristics of other elements of the same work. To him, these elements determine the value of a piece of art. 
In Berlyne (1974), he referenced his earlier work, Berlyne (1967), where he connected hedonic values of paintings with fluctuation in arousal. He hypothesized that aesthetic patterns produce their hedonic effects by acting on arousal-a counterpart of the previous conviction that works of art give pleasure through their emotional impact. [p. 8]. Berlyne laid the foundation for "measuring" the aesthetic effects of a painting. That seemed to be the first step towards having a universal standard for assessing visual arts objectively. Subsequently, an urge has emerged in quest for deeper understanding of what makes an art beautiful.

Yet, for centuries, the question of "what beauty is" has struggled with determining an adequate definition. Some observers have sought to understand beauty in terms of the characteristics of the objects. It has been suggested that in visual art (e.g., architecture), symmetry, proportion, harmony and so on, may summarize "beauty." Ramachandran, one of the two pioneers in the field of Aesthetics, with Hirstein, identified symmetry and "balance" among ten elements (later, eight elements) present in great paintings, which attract people to their beauty. Ramachandran and Hirstein (1999) presented a theory of human artistic experience related to neural mechanism. They suggested that artists either consciously or unconsciously deploy certain rules or principles (laws) to excite the visual areas of the brain. They presented many of those laws together and provided a coherent biological framework that when considered simultaneously, and viewed in a biological context, begin to make sense. They saw three bases to their argument. First, what might loosely be called the "internal logic" of the phenomenon they called laws. Second, the evolutionary rationale: the question of why the laws have evolved and have that particular form (e.g. grouping facilitates object perception).

Third, the neurophysiology (e.g. grouping) occurs in extra striate areas and is facilitated by synchronization of spikes and direct limbic activation. All three of these need to be present; and must inform each other, before one can claim to have understood any complex manifestation of human nature, such as art. Many earlier discussions of art, in their view, suffer from the shortcoming of viewing the problem from just one or two of these perspectives. According to their theory of art, evaluation of an artistic object must have at least three components: (a) the logic of the art and universal rules or principles for their evaluation; (b) the evolution of the rationale; (c) and determination of the brain circuitry involved. Thus, they proposed eight laws of "artistic experience," as the key characteristics of arts.

Semir Zeki, also one of the founders of the Aesthetics field (with Ramachandran), developed an outline of a theory of aesthetics that is biologically based, Zeki (1999). He considered that work an outline since he thought that the knowledge of how actually brain works was still very sketchy then. Yet, he noted, "all visual arts obeyed the law of brain and must therefore obey the laws of the brain." He said, "...art is an active process, whose function constitutes an extension of the function of the visual brain." (p. 7).

Solso [2003] connected evolution of conscious thought with the evolution of art. His basic thesis was that when humans evolved conscious awareness, they were able to make conscious association between pleasurable experiences and stimuli. That empowered people to value art. 
Reber and associates (2004) asked, "what is beautiful," going back to Plato. They proposed that aesthetic experience is a function of the perceiver's processing dynamics. They noted three factors, which emerge from their literature review: goodness of the form, symmetry and figure-ground contrast, which "protypically" creates fluency in a painting. Accordingly, they suggested that these elements are at the heart of creating aesthetic pleasure.

Silvia (2005) gave a historical perspective and emphasized the importance of the modern science of "emotions," because it has much to offer the study of aesthetics, opening an expansive set of new ideas. He suggested that appraisal of theories make new predictions about emotional responses to art, expanding the domain of aesthetic emotions beyond positive emotions such as interest and enjoyment. He developed the Model of Appraisal and Interest in Art that informed the study of aesthetics.

Silvia, et al, also proposed that spectators of paintings differ in emotional response to artwhich challenges the arousal model. Their artistic training affects their judgment. Knowledge about art affects the emotional experience of art. Emotional concepts within the Berlyne (1971) tradition, however, have emphasized affective terms such as preference, reward value, aesthetic response, hedonic response and affective response. He also observed that would be unproductive to lump different emotions, each with distinct causes and consequences, under one umbrella. Besides, Silva noted that according to some studies the rating of interest differs from rating of enjoyment. (p. 351). Based on these findings, he suggested an alternative Arousal Model, following in the footsteps of Berlyne.

Dutton (2009) suggested an interesting and fascinating view that arts are by-products of an evolutionary adaptation, which is an instinctual trait. Therefore, arts help us to survive because they are critical to our wellbeing.

Ishizu and Zeki (2011) developed the Brain Theory of Beauty. They addressed the question that has been asked for many centuries, namely what constitutes beauty. They note that Burk (1757) suggested "Beauty is, for the greater part, some quality in bodies acting mechanically upon the human mind by the intervention of the senses." Ishizu and Zeki (p.1). They concluded that this definition suggests presence of a consciousness of "beauty" that can be stimulated by any and all senses. But their reading of the relevant humanistic literature suggested that the first alternative has been more favored by those who have debated on the subject, namely that there is a single faculty of "beauty" into which different senses feed. Yet, they believed that alternative was echoed in Burke's definition. Overall, their research was motivated to explore how brain activity might be organized during the "experience of beauty." They investigated whether beauty from different sources activated the same areas of the brain. Their data comprised 21 subjects' brain responses to stimuli (paintings and excerpts of music), using fMRI imaging. They selected three sets of stimuli"beautiful," "indifferent" and "ugly," in each category. They concluded that there is a faculty of beauty that does not depend on modality through which it is conveyed. In their experiment, at least two sources of stimuli (and probably other sources, they note) had the same effect on their subjects. These findings led them to formulate their "brain theory of beauty."

Gopnikc (2012), focused on the biological bases of human behavior. He concluded that aesthetic experiences emerge from the interaction between sensory- motor, emotionsvaluation, and meaning, encompassing knowledge neural systems. 
Hager and associates (2012) conducted two studies, using 193 cases in one and 147 in another, for their experimentation. They analyzed factor structure of an aesthetic experience and developed the Art Reception Survey (ARS), which is a template for assessment of characteristics of an artwork. They identified a 6-factor structure, including recipients' cognitive involvement, positive or negative affective appraisal and creativity, and information about knowledge and comprehension about artwork for judgment of pleasure, likeability, or beauty.

Eric Kendal, a 2000 Nobel laureate, suggested in Kendal (2012) that human brain assigns meanings of different degrees to the various shapes, colors and movement seen in a beautiful artwork. He noted, those effects illustrate that the aesthetic pleasure is not an elementary sensation (like the feeling of hot or cold, or the taste of bitter or sweet). He noted that they represent a higher-order evaluation of sensory information, processed along specialized pathways in the brain that estimate the potential for reward from work of art that people view. Kendal noted that sudden recognition of an $A H A$ moment by the viewers of art is because they suddenly see the artist's communication shared with them. They see that creative process, which characterizes every human brain, leads us to see the truth underlying both the beauty and the ugliness depicted by the artist. (E book: Loc 5019 of 9484).

Vartanian and Skov (2014) focused on the visual modality and paintings to evaluate aesthetic experience associated with exposure to works of art. They selected 15 studies through Boolean searches in Pub-Med (p. 53) to conduct a quantitative meta-analysis of $15 \mathrm{fMRI}$ studies of response to paintings. Of the fifteen studies they used, 13 had a small number of subjects, 8-21, with remaining two of larger numbers, 40 and 87 cases. Yet, Vartanian and Skov created a large sample, integrating all of those cases. They used the Activation Likelihood Estimation (ALE). They confirmed that viewing paintings engage not only systems involved in dual representation and object recognition, but also structures underlying emotions. They confirmed three hypotheses that: (1) viewing paintings activates areas in the visual cortex including "the lingual gyrus and the middle occipital gyrus, as well as the fusiform gyrus." They noted that these activations could be attributed to the processing of various features of the stimuli embedded within paintings; (2) the stimulating effect of "representations," such as landscapes, in paintings on the brain (3) the activation of the anterior insula bilaterally. The most interesting, and somewhat "unexpected," result of their study was finding activation in the posterior cingulate cortex bilaterally. They noted that this region is affected when viewers "maximize the utility" of being in the "moment" (while viewing a painting), and "disconnect themselves" from their external world. Their third finding suggests that paintings may have a powerful effect on perceptive viewers' inner emotions and thoughts. The same logic suggests that paintings can have a meditative effect, as mediation defined in the Merriam-Webster dictionary.

The theoretical body of literature we have reviewed supports a major proposition that paintings are stimuli to the human brain, and can indeed immerse the viewers in moments of pleasure when they encounter a positive aesthetic experience. Those literatures support our presupposition that Abstract Romanticism has affective properties that impart positive emotional effect on viewers. 
As we noted in Amirmostofian and Mozayeni, et al, along with the theoretical Aesthetics research, empirical knowledge has also moved notably on a fast trajectory in the last ten years. Recent methodology has expanded research to development of the Neurasthenics field by focusing on the viewers' experience with beauty and appreciation of arts at the levels of brain function. In this line of research, it is widely accepted that visual aesthetics, namely the capacity of assigning different degrees of beauty to certain forms, colors, or movements, is an innate human trait. The empirical research also indicates that when viewers of paintings perceive them beautiful, their brain is stimulated. Among them are: Cela- Conde (2004), Kemp and Cupchick (2007), Silvia (2007), a Joint study by Johns Hopkins Brain and Mind Center and the Walter Museum (2010), for which we have found no journal publication record, Lacey and associates (2011), Tsuklura and Gabeza (2011), Ishuzi and Zeki (2011), Vessel [2013], and Vartanian and Skov [2014].

Studies of the human brain response to the arts (e.g., visual arts) use either self-reported responses of the subjects in an experiment or directly observe subjects' brain responses to stimuli, using $\mathrm{fMRI}$, albeit substantial financial and administrative cost differences. With the advent of technology, the latter has become the predominant method. We review both methodologies and address the striking similarities of their outcome.

Cela-Conde (2004) used magneto encephalography (MEG) on eight (8) university students to study the localization of brain areas activated during the visual perception of aesthetic objects. That research found that activation of the Prefrontal Cortex in the Human Visual Aesthetic Perception, tied the human experience (the determination of specific brain circuitry involved) points to understanding of the origin of the human response to beauty.

Silvia (2005) evaluated the modern science of "emotions" and how appraisal theories of emotion inform the study of aesthetics, making new predictions about emotional response to arts, within the Berlyne's tradition.

Kemp and Cupchik (2007) used the survey method to examine the effect of a selection of paintings on the human mind. Their data included 48 undergraduate students enrolled in a Psychology course at the University of Toronto, who received course credit for their participation. They recorded the subjects' mood before the experimentation weekly and after their viewing of a selected set of paintings. In sum, they examined the ways that the subject matter and style can predict emotional experiences of artworks, particularly when viewers' individual differences in their study were taken into account. To the best of our knowledge, this work is one of very few studies based on a survey method. Unfortunately, their very small sample size and highly specific population, hinders generalization of their results. Nonetheless, their findings are congruent with the theoretical aesthetic literature we have reviewed.

Silvia and Brown (2007) also used a survey method with similar sample limitations. Their sample included fifty-eight (58) undergraduate students. They conducted a multi-level analysis, observing anger, disgust and negative aesthetic emotion responses to artwork. They concluded that these emotions are central to individuals' appraisal of art, why people reject or embrace artworks. Their sample had the same limitations as the Kemp and Cupchick (2007). 
On the other hand, several studies have used fMRI. These studies, in general, have a small sample due to the nature of the work involved. Therefore, their results cannot be generalized.

Lacey and associates (2011) studied the responses of eight (8) subjects to 50 paintings and observed their effect on their brains. Participants liked art images more than non-art images. They suggested that responses to one questionnaire did not necessarily influence responses to another and that these aspects of esthetic experience were independent for non-art images while, for art images, esthetic pleasure was independent of the other ratings. They corrected for the limitation of their small sample size to be able to generalize it.

Tsuklura and Gabeza (2011), based on their study of 22 subjects, successfully encoded the brain responses to stimuli (painting and excerpt of music) activity. They reached three results: (1) activity in the right orbitofrontal cortex increased (linearly) as a function of attractiveness rating; (2) activity in the left hippocampus increased as a function of subsequent memory; (3) functional connectivity between these orbitofrontal and hippocampal regions were stronger during encoding of attractive faces, leading to activation of regions associated with reward and memory. They could clearly observe activation of the regions of brain associated with reward and memory and thus a positive bias toward attractive faces, and beauty in general.

Vessel (2013) used fMRI to scan the brain of sixteen (16) subjects. All of them saw the same series of 109 color artworks in a randomized manner. They investigated the differences in subjects' aesthetic responses to address the shortcomings they perceived of in previous neurasthenics research. In their opinion, those researchers "tended to utilize art pieces that were manipulated in a manner intended to have a consistent effect on observers' preferences or that were generally highly regarded and often, widely known (e.g., The Mona Lisa)." (P.2) They studied the effect of paintings that were not admiredartwork to reveal viewers' unbiased aesthetic experience. Their material included a set of two- dimensional artworks spanning over a variety of periods, regions, styles and genre from Fifteen to Twenty Centuries, Western and Eastern works, both representational and abstract genres. The artworks were original from museums. The painting categories were "beautiful, "strange," or even "ugly." They used several different analyses and created a rich data set. They noted that aesthetic experience involves not only preference, it encompasses a variety of emotional responses ranging from "beauty to awe," sublimely and in a variety of other emotions, which are often "knowledge-based." (p.3). Their results showed highly individualized responses, meaning that viewers had very little agreement. Yet, in conclusion, they noted: "Great art is, almost by definition, universal: the wide appeal it commands comes from a connection with fundamental aspect of human nature and human cognition (Kant 1790).

Amirmostofian and Mozayeni (2016) and Mozayeni and Amirmostofian (2016) used the self-reported survey method to examine the effect of Abstract Romanticism on 318 subjects. Amirmostofian and Mozayeni used several nonparametric estimations, which generated strong and significant evidence for the effect of paintings in general, and as a case study, of Khavarani's, on the subject's brain. Whereas, Mozayeni and Amirmostofian used parametric modeling for 12 Multivariate Generalized Regression Models (MGLM) 
regressions and confirmed the findings they had reported in Amirmostofian and Mozayeni study.

As we noted earlier, studies of the human brain response to arts have used either selfreported responses of the subjects in an experiment or by direct observation of the fMRI of brains' responses to visual arts stimuli.

Yet, striking similarity emerges from studies of responses to visual arts- including paintings, whether observed in fMRI studies of subjects' brains or their self-reporting responses, as a two-phase study by the Walter Museum and the Center for Mind/Brain at Johns Hopkins University, has shown. Dr. Gary Vikan, the Director of the Walter Museum then, noted, 'What you'll find in this show is that there is an amazing convergence. The people who came to the museum liked and disliked the same type of shapes as the people in the lab and the people in the imaging machine. It was amazing how tight the clustering was-it was like art." [Vikan, Beauty and Brain Revealed, Dana Foundation, News and Views..., October 29, 2013].

The empirical and theoretical researches reviewed, jointly provide strong support that works of art are stimuli to the brain and thus affect viewers' mood, albeit differences in details. They form the theoretical pillar of our research.

With that foundation, we evaluate what Boime, et al., observed in Khavarani's paintings. Describing one of his paintings-Purpose 2004 [p. 185], Boime said, ".... For Khavarani this wilderness niche is far removed from the social ills that afflict the public sphere, but it offers a model of his particular destiny. One's purpose may be held in secret, while expressing itself as a healing balm for the receptive perceiver." (p.184).

Here, we attempt again to evaluate if the Boime's interjection stands yet another formal investigation. We therefore test our postulate hypothesis that Khavarani's paintings calm viewers, and elevate their mood to a joyful state. Considering hundreds of worldwide affirmations, including many from patients at the Beverly Hills Cancer Center, where several of Khavarani's paintings have been on display for more than a decade, we strive to evaluate the validity of those informal observations as well.

To make this report self-contained, we borrow heavily from our previous research manuscripts, including the literature review, our survey data and their description. With that background and within the context of the theoretical and empirical literature reviewed here, we present our research method and results. We verify a priori conjecture that Khavarani's 'paintings have characteristics that impart positive effect on the minds of the spectators, in this case, irrespective of subjects' age, gender and base mood.

In the following section, we discuss our method and data, followed by a summary of our findings and discussion.

\section{Methodology, Data and Results}

As noted earlier, our research objective is to examine the effect of the style of Khavarani's paintings, known as Abstract Romanticism, on viewers' psyche, using a pattern analysis of 
time series that traces individuals' moods. The full description of our data and the method of our survey and data collection process are fully discussed in Amirmostofian and Mozayeni (2016). The primary data set for this analysis include the survey of 252 individuals who visited three art galleries. Each subject visited all three galleries. One of the galleries was Khavarani's, which housed exclusively his paintings. We refer to this gallery as experimental gallery for assessing the effect of his paintings on viewer's mood. Approximately, one third of the individuals visited the experimental gallery first, and then the other two, about one third visited the experimental gallery second and about one third visited the experimental gallery last of the three. Before and after each visit, the participants reported their mood on a ten-point Likert scale, of which only even values are used as were in Amirmostofian and Mozayeni, et al. Thus, here we consider a six-point scale $(0,2,4,6$, 8 and 10). With these data in hand, we wish to determine, whether, or not, viewers' moods change are related to their gender, age or the type of art they have viewed in the gallery they visited (experimental or not).

As noted earlier, we borrow these data from Mozayeni and Amirmostofian (2016). The primary data set we use includes gender, the age group, and the mood scores for 252 individuals before and after vising three galleries. Mood scores are recorded by the order of the subjects' visits. We then generate additional data from the primary 252 cases we have. The additional data are necessary for conducting a Pattern Analysis. We conduct several graphical analyses and formal tests, including the Pearson's Chi-squared tests for association of age, gender and the order of visits, and a log linear analysis for evaluation of deviance of the models we use.

The first data set we use contains 252 rows, one for each subject, and columns reflecting gender, the age group (there are 7 groups, 5-10, 11-15,16-20,...., 41-50 and over 50) and the order in which the subjects visited the three galleries, six columns recording the "before" and "after" mood scores for visiting each of the three galleries in the order of their visits. Additionally, three difference scores reflect the changes in their mood resulting from the visit to each gallery. Three more columns give only the signs of the differences in the mood scores, and three yet more give the direction of the mood change, the pattern (e.g., same, up or down). One column in our data concatenates the description of changes, e.g., upsamedown (up, same, down) and another collapses the infrequent descriptions to "other." The last column collapses the more extreme age groups, as shown below. This file is wide in the sense that six scores appear in each row. We make a linear transformation of the wide data to manage it for analysis, as we describe below.

\section{Scores by Time Wide}

A file with subjects, their genders, age groups and order and the six time traces scores is a "wide" data set, which the computer program cannot handle. To overcome that constraint, we jitter the data to change its length.

To illustrate the complex data distribution visually, we need to discern their plots by forming subgroups at several overlapping points. To achieve that, we systematically (rather than randomly) jitter the time traces variable. In this process, we are also reshaping the "wide" data to "long." 
We then create Mosaic Plots for pairwise combination of Age Group, Gender and Order to show their patterns visually.

\section{Age Group by Gender Mosaic Plots}

Below are mosaic plots for Age Groups by Gender from which we note the need to collapse the infrequently occurring age group.

Age by Gender

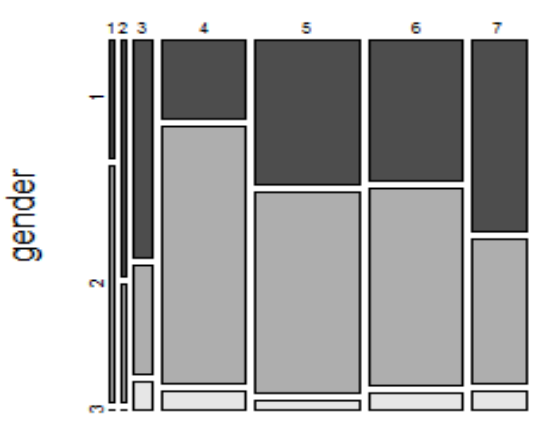

age group
Age by Gender

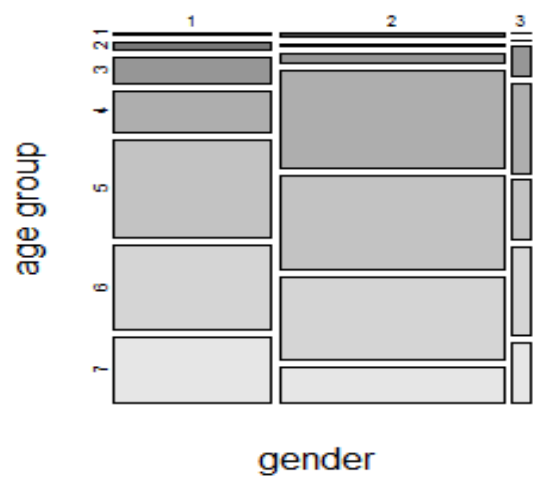

Figure 1: Pattern by Age and Gender

We also generate plot for individuals' time series traces in the order they visited the three galleries, as shown below.

\section{Traces of Subjects' Scores by Gallery}

The plot for the time series traces of individual scores are graphed below. The order in which the subjects visited the galleries are distinguished by color and then trellised. The plots make it obvious that visiting the experimental gallery had an notable effect on the viewer's mood, consistent within each order. Visiting the experimental gallery caused the subjects' scores to increase. The data clearly show that this was not true for the other galleries. 


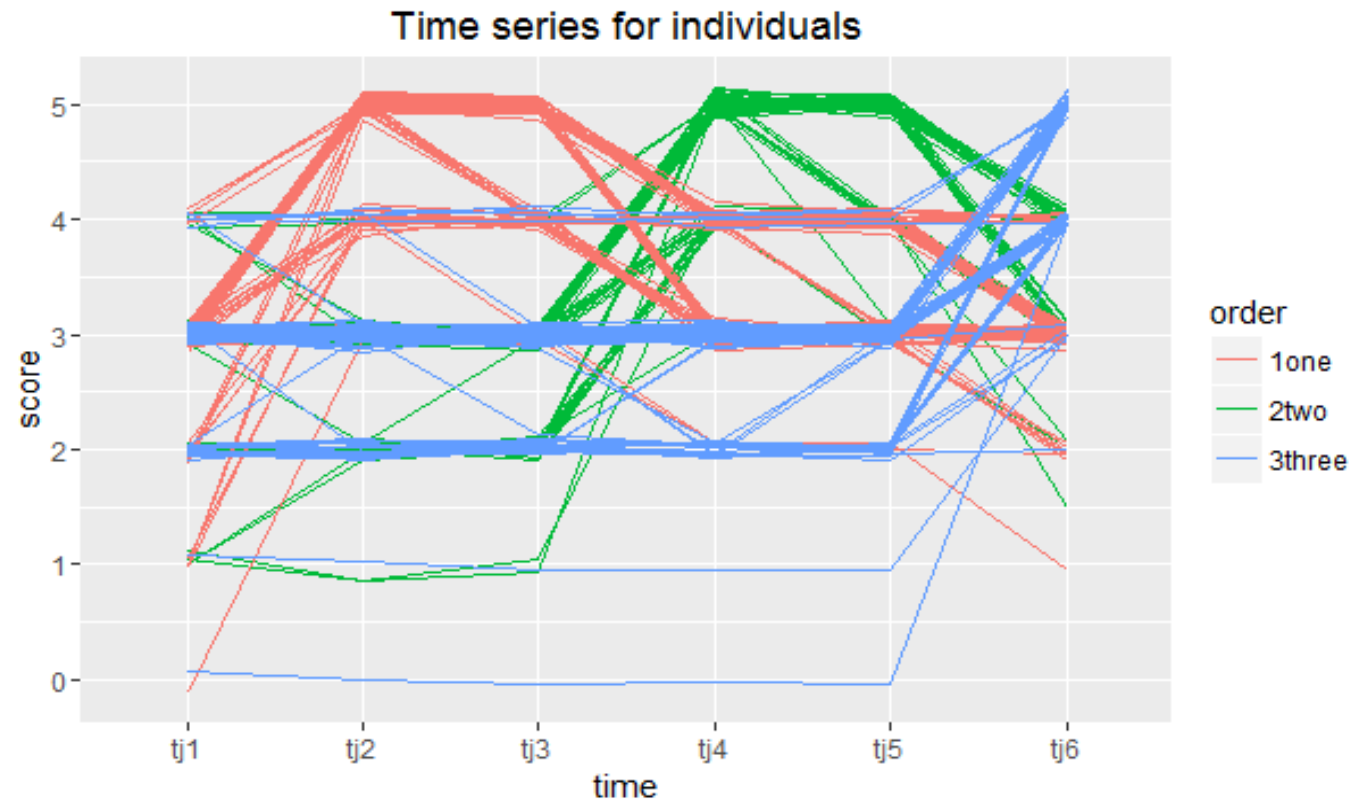

Figure 2: Time Series for Individuals
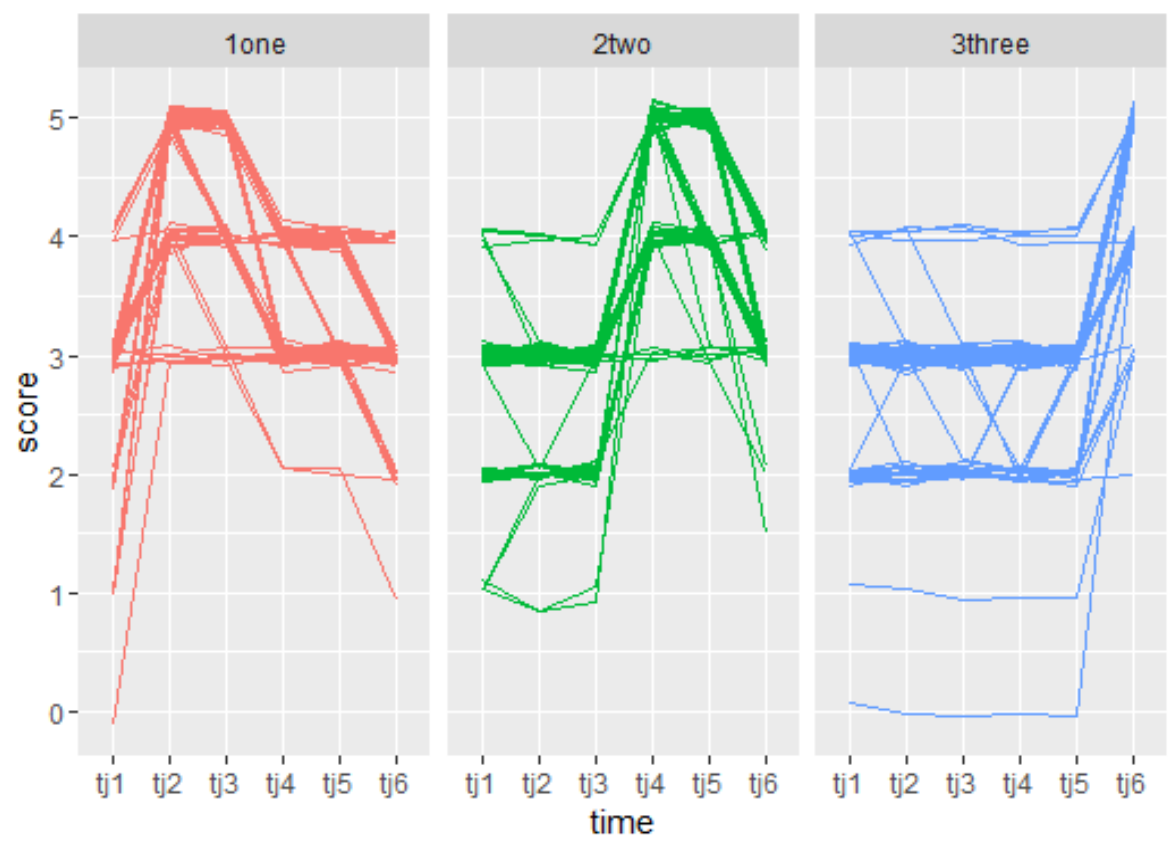

$$
\begin{aligned}
& \text { order } \\
& \begin{array}{l}
\text { - 1one } \\
\text { - 2two } \\
\text { - 3three }
\end{array}
\end{aligned}
$$

\section{Figure 3: Time Series for Individuals Jittered}

The two sets of graphs above plot scores for subjects' mood change and their time traces. In these graphs, scores were jittered to avoid overplotting. 
Of note, the leger shows the coding of the data, necessary for overriding the computer alphabetical reading of the words, by placing digits before the numbers scripts (i.e., 1one, 2two, 3three).

Scores on the Y-axis are the Likert scales for mood (even numbers between 0 and 10).

From these plots, we see that for the group of subjects visiting the experimental gallery first (the red group), almost every subject experienced an increase in their mood and usually the after mood from the first gallery, the experimental gallery, was their mood before entering the second gallery. Almost always, the subjects' moods declined while in the second gallery, where they tended to stay when entering the third gallery and for the most part they remained while at the third gallery. Subjects visiting the experimental gallery second (green) and those visiting the experimental gallery last (blue) had experiences similar to the first group, albeit in different orders.

\section{Analyzing Patterns}

In as much as there are only a few patterns of scores for the subjects, we may ask if there are relationships between pattern and gender, or age group, or the order (the order of visits). For this analysis, we organize the data by combinations of these variables (there are 64 such combinations) and find counts for each combination as in "pivot tables."

\section{Age by Pattern}

We have crossed tabulated patterns by age group in two tables, which are omitted for brevity and available upon request. In the first table we show cell frequencies, while the second table gives cell proportions with columns (age groups) summing to one. The chisquare test for independence indicates that there is not a significant association between age group and pattern of scores. This fact is illustrated in the mosaic plot below.

The Pearson's Chi-squared test is $X^{2}=16.42$, with the degree of freedom of 15 and $P=0.35$. With the high Chi-squared and low $\mathrm{P}$ values, we reject the null hypothesis.

\section{Gender by Pattern}

We cross tabulated Patterns and Gender and constructed cell frequencies and cell proportions with columns (genders) summing to one. The Chi-square test for independence seems to indicate that there is a significant association between gender and pattern of scores. This relationship is illustrated in the mosaic plot below, Figure 4. However, we note the sparsity of data for gender 3 and observe that the expected cell frequencies for gender 3 are all well below the generally acceptable rule of 5 and therefore we should not trust the p-value of this chi-squared test. Therefore, we repeat this test with only genders 1 and 2 and find no significant association with Pearson's Chi-squared test, $\mathrm{X}^{2}=26.17$.

\section{Mosaic Plots: Gender and Pattern, Age and Pattern and Order and Pattern}


Below, in Figures 4, we present the plots for Gender and Pattern and Age and Pattern. In Figure 5, we present the Order and Pattern plot. We then focus on the Order by Pattern results.

\section{Gender by Pattern}

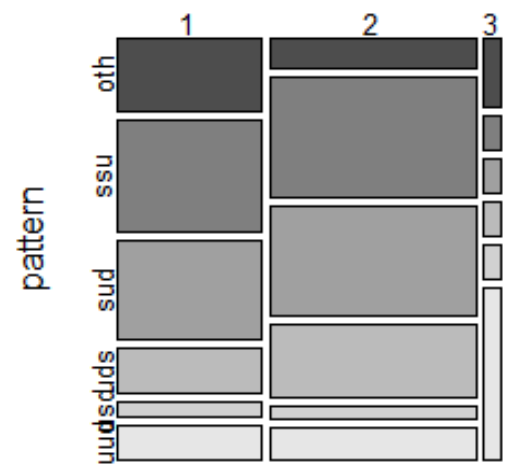

gender
Age by Pattern

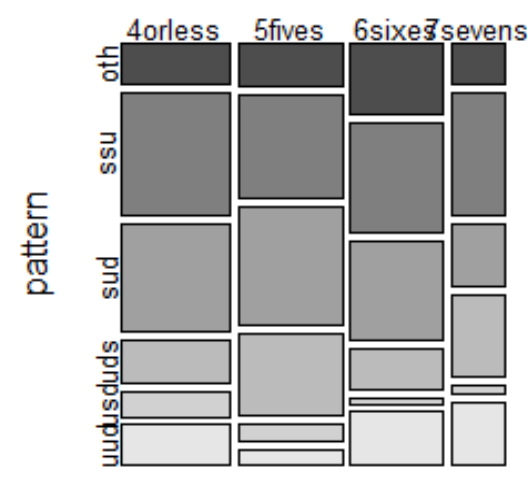

age group

Figure 4: Gender by Pattern AND Age by Pattern

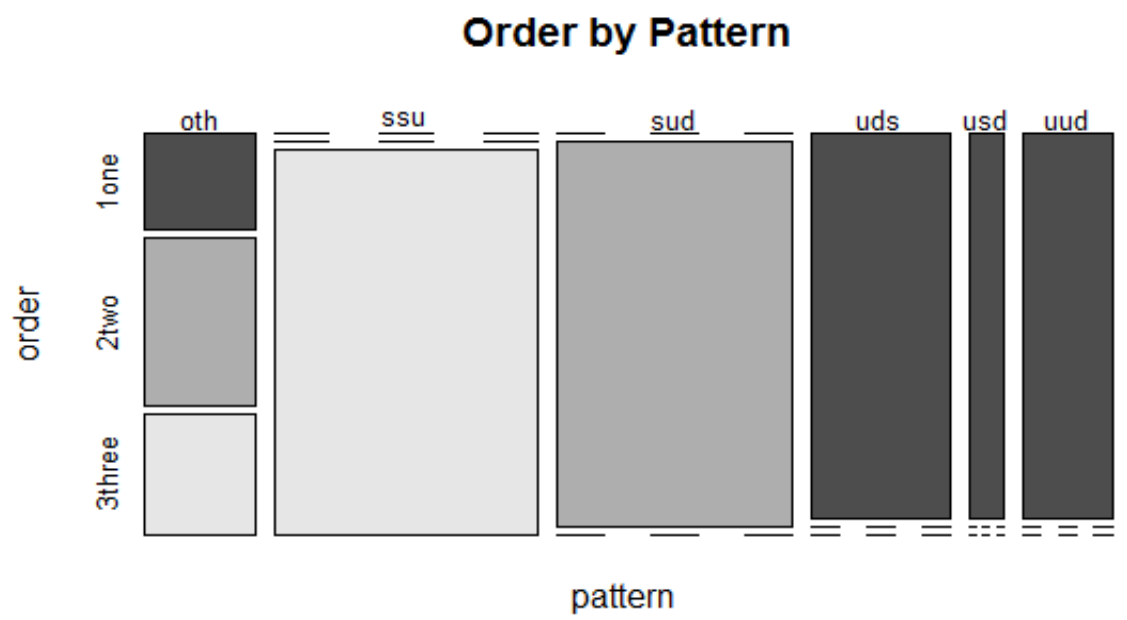

Figure 5: Order by Pattern 


\section{Order by Pattern}

The mosaic plot of Order by Pattern, Figure 5, shows that for order one (the darkest shading), the predominant patterns are up-down-same, up-same down and up-up-down. In other words, when the subjects visit the experimental gallery first, their mood is initially increased and then varies subsequently. For order two, the mood increases while visiting the second gallery, which for this order is the experimental gallery.

The analysis of the relationship between the order in which the subjects attended the three galleries and their pattern of response reveals the strong expected association, having $x^{2}$ $=441.65$, with the degree of freedom of 10 and $\mathrm{P}<2.2 \mathrm{e}-16$.

The Chi-squared value, $x^{2}=441.65$, emphasizes the very strong association between Order and Pattern. In fact, there is really no need to subject the data to an hypothesis test. We see from the plots that when a subject visited the experimental gallery first, $31 \%$ of the time their mood increased while attending the experimental gallery and then declined while visiting each of the other two galleries. Forty-eight percent of the times, those visiting experimental galley first increased mood while in that gallery while mood declining in gallery two and remaining at the declined level while in the third gallery. Finally, for "Order One," $12 \%$ of the subjects experienced the same mood that they had leaving gallery one, while in gallery two and then experienced mood decline in gallery three. Essentially, those visiting the experimental gallery first experience increased mood in the experimental gallery, but eventually their mood declines after leaving gallery one.

For Order Two, that is the subjects visiting the experimental gallery between visits to other galleries, mood stays the same in the first gallery, rises while in the experimental gallery and then subsequently declines.

For Order Three, visits to the first two control galleries have little or no effect on subjects' moods. but when visiting the experimental gallery, their moods elevate (score increases). We have plotted the Order by Pattern in Figure 5.

Next, we present the analyses of the Deviances of our variables.

\section{Loglinear Regression Models}

For Deviance Analysis, we use loglinear models for Gender and Pattern, Age and Pattern and Order and Pattern. We report the results below.

\section{Regression Results for Gender and Pattern}

The log-linear models show the distribution of subjects by gender or age group, etc. The main effects do not tell us about the relationship between variables, e.g., between Gender and Patterns. For these relationships we examine their interactions.

In the analysis of deviance data, we observe that the Gender by Pattern interaction's s deviance is 1.713 on 5 degrees of freedom. The distribution of deviance is approximately chi-square, so this interaction is clearly not significant in as much as the mean of a Chisquare distribution is its degrees of freedom and its variance is twice that. 


\section{Age and Pattern}

The deviance associated with the Age by Pattern interaction is 26.958 on 15 degrees of freedom. This chi-square value for a two-tail test gives a P-value, approximately 0.058 . Thus, the distributions of Patterns over Age groups are not quite the same. We note that age group 5 has considerably more updownsame patterns than the other age groups. This observation echoes the stability of the mood for older participants, among our age groups.

\section{Order and Pattern}

The Order by Pattern log linear models was unable to produce estimates of the interaction terms due to sparsity in the Order by Pattern two-way analysis. It may be possible to obtain Bayesian estimates of these interactions because Markov Chain Monte Carlo methods will automatically impute missing values. However, the data shows obvious association between Order and Pattern; and thus there is no need to model the data. The association between Order and Pattern is obvious.

\section{Summary and Conclusion}

We have conducted a Pattern Analysis of the effect of the painterly style of Abstract Romanticism, Khavarani's genre of painting, on viewers' psyche. We have analyzed the time series traces of individual moods after vising three galleries, one of which was Khavarani's gallery, which exclusively housed his paintings.

We conduct several graphical analyses and formal tests, including Pearson Chi-squared tests for association of Age, Gender and the Order of visits. The Chi-squared test for Order, $X^{2}=441.65$, with the degree of freedom of 10 and $P<2.2$ e -16 , emphasizes the very strong association between Order and Pattern. Essentially, those visiting the experimental gallery first (Gallery One) experienced increased mood while in the experimental gallery, but eventually their mood declined after leaving Gallery One. For Order Two, that is the subjects who visited the experimental gallery between visits to other galleries, moods stayed the same in the first gallery, rose while in the experimental gallery and then subsequently declined. For Order Three, subjects visited the first two controlled galleries, followed by their visits to the experimental gallery, shows little or no effect on the subjects' moods; but when visited the experimental gallery, their moods elevated (increased).

We also used several iterations of log-linear estimation models for our variables and several Deviance tests. In all cases, our results strongly support our a priori hypothesis that Khavarani's painterly style has a positive effect on viewers' mood, as the UCLA professor of Art Social History, late Albert Boime, informally suggested about "Abstract Romanticism."

Our analyses strongly suggest that Khavarani's paintings have a powerful effect on viewers that in fact can "last." His paintings have characteristics that affect the viewers' brains and thus their psyche. This research confirms the findings of Amirmostofian and Mozayeni (2016) and Mozayeni and Amirmostofian (2016), albeit their differences of modeling and methodologies; and reverberates Eric Kendal's observation in the Age of Insight, who says: "When we look at a beautiful work of art, our brain assigns different degrees of meaning to various shapes, colors, and movements we see...." [ebook, elSBN:978-1-58836-930-7, Page 5380]. 
The method of our data collection, as we first reported in Amirmostofian and Mozayeni (2016) et al., and a series of parametric and nonparametric models we use there and in Mozayeni and Amirmostofian (2016) et al., with the results of our analyses here, lend a robust support for external validation of our sample. Simply put, we propose that the viewers of Khavarani's paintings in our sample are representative of the population at large. Our formal results, withstanding hundreds of testaments, strongly support the hypothesis that Khavarani's paintings affect the viewer's psyche, and perhaps as Vartanian and Skav (2014) suggest, when receptive subjects view his paintings, they "maximize the utility of the moment" and "disengage" from their external world, and experience a "joy," similar to "meditative joy."

\section{Authors' Notes}

Contributions: (1) Mozayeni: Literature Review, verification of raw and coded data, drafting the manuscript and all its revisions, journal submission and follow-up work. (2) Karl Heiner: Statistical methodology, design of the Pattern Analysis data, execution of analyses and interpretation of the results, review and approval of manuscript drafts. (3) Amirmostofian: The initial research question, conception and design of the primary data set, acquisition of the primary data, coding and entry of data, review and approval of manuscript drafts.

Acknowledgments: (1) We acknowledge competent and dedicated research assistance of Ms. Enkeleda Cuko.

Statement of Conflict of Interest: The authors have NO affiliations with or involvement in any organization or entity with any financial interest (such as honoraria; educational grants; participation in speakers' bureaus; membership, employment, consultancies, stock ownership, or other equity interest; and expert testimony or patent-licensing arrangements), or nonfinancial interest (i.e., professional relationships, affiliations, knowledge or beliefs) in the subject matter or materials discussed in this manuscript.

\section{References}

Amirmostofian, P. and Mozayeni, S. (2016), Art for New Consciousness, Art Humanity: An Empirical Investigation of Aesthetical Sciences, Vol. V, No. 1, 27-46. Khavarani's Paintings, International Journal of Social Sciences, Vol.
http://www.iises.net/international-journal-of-social-sciences/publication-

Anjan, C. and Vartanian, O. (2011). Neuroaesthetics, Trends in Cognitive Sciences. Vol. 18, No. 7., 370-75.

Baker, Nathanille, L. and Kevin M Gray, Jittering: ASAS ${ }^{\circledR}$ Macro to Shift Overlapping Plots, analytics.ncsu.edu/sesug/2009/SD002.Baker.pdf Retrieved March 21, 2016.

Berlyne, D. E. (1971). Aesthetics and Psychobiology, Century Psychology Series, Appleton Century-Crofts. Educational Divisions, New York.

Berlyne, D. E. (1974). The new experimental aesthetics. In D. E. Berlyne [Ed.]. Studies in the new experimental aesthetics, 1-25. Washington

D.C: Hemisphere 
Boime, A. (2008 a). The Birth of Abstract Romanticism, Art for a New Humanity, Art for a New Consciousness, Rumi and the Paintings of Kamran Khavarani. Sybil City Book Company, San Francisco, CA. ISBN: 978-0-9816739-2-9, Collector's Edition.

Boime, A. (2008b, July 28). From the Desk of Albert Boime, Department of Art History, UCLA. http://albertboime.com/Letters.cfm Retrieved 11/11/2015.

Burgaso, G. (2014). http://mic.com/articles/106504/science-shows-that art-is having fantastic effects on our brains and bodies Retrieved August 1, 2015.

Carmerer, C. F., G. Loewenstein and M. Rabin. (2003). (ed.) Advances in Behavioral Economics (The Roundtable Series in Behavioral Economics) [Print Replica] Kindle Edition.

Cela-Conde, C., and associates. (2004). Activation of the prefrontal cortex in the human visual aesthetic perception. Proceedings of the National Academy of Sciences the United States of America. 101(16), 6321-6325 (Published online before print April 12, 2004, doi: 10.1073/pnas.0401427101.) PNAS April 20, 2004 vol. 101 no.16 6321- 6325.

Cupchik, G. C. (2009). Viewing Artworks: Contributions of Cognitive Control and Perceptual Facilitation $\begin{array}{lllll}\text { to Aesthetic Experience. Brain and } \quad \text { Cognition, } & 70 & \text { 84-91. }\end{array}$ https://doi.org/10.1016/j.bandc.2009.01.003

Daniel, Wayne W. (1990). "Kruskal-Wallis one way analysis of variance by ranks". Applied Nonparametric Statistics (2nd ed.). Boston: PWS-Kent. pp. 226-234 [http://psych.unl.edu/psycrs/handcomp/hckw.PDF Retrieved 11/18/15.

Danto, A. C. (1983). The Transfiguration of the Commonplace, A Philosophy of Art. Harvard University Press.

Dutton, D. (2009). The art Instinct: Beauty, Pleasure and Human Evolution, Bloomsbury Press, New York.

Gopnick, B. (2012). Aesthetic science and artistic knowledge. Aesthetic Science: Connecting Minds, Brains and Experience (Shimamura, A.P. and Palmer, S.E., eds). 129-159, Oxford University Press.

Holt, J. (2013). Neurasthenics and Philosophy, SAGE Open, July-September $\quad 2013: \quad 1-7 . \quad$ DOI: 10.1177/2158244013500677sgo.sagepub.com. Retrieved 8/31/15.

Hager, M., Hagman, D., Danner. D. and Schankin, A. (2012). Assessing Aesthetics Appreciation of Visual Artworks-the Construction of the Art Reception Survey (ARS), Psychology of Aesthetics, Creativity and the Arts. Vol. 6(4), Nov 2012. 320-333. https://doi.org/10.1037/a0028776

Ishizu, T., Zeki, S. (2011). Toward A Brain-Based Theory of Beauty. PLoS $\quad$ ONE 6(7): $\quad$ e21852. doi:10.1371/journal.pone.0021852. Retrieved August 2, 2015.

Kandel, E. (2012). The Age of Insight. Random House, Inc. New York. [The Age of Insight: The Quest to Understand the Unconscious in Art, Mind, and Brain, from Vienna 1900 to the Present. Kindle Edition]

Kemp, S.W.P. and Cupchik, G.C. (2007). The Emotionally Evocative Effects of Paintings. Visual Arts Research, 33 no 1, 72-82.

Lacey, S., Hagtvedt, H. van essa, M., Anderson, A., Randal, S. (2011). Art for reward's sake: Visual art recruits the ventral striatum. Neurolmage, 55.1. ProQuest Psychology Journals. Retrieved 7/30/2015. https://doi.org/10.1016/j.neuroimage.2010.11.027

Marshall, A. (1920). Principles of Economics (Revised ed.). London: Macmillan; reprinted by Prometheus Books. ISBN 1-57392-140-8. 
Mozayeni, S. and Amirmostofian, P. (2016), Comparison of Parametric and Nonparametric Modeling: Aesthetic Effect of Kamran Khavarani's Paintings, International Journal of Social Sciences, Vol. V, No. 1, 72-92. http://www.iises.net/international-journal-of-social-sciences/publication- detail$\underline{453}$

Ramachandran V.S. and Hirstein, W. (1999). The Science of Art: A Neurological Theory of Aesthetic Experience. Journal of Consciousness Studies, 6, No. 6-7,15-51.

Reber, R., Schwarz, N. and Winkielman, P. (2004). Processing Fluency and Aesthetic Pleasure: Is Beauty in the Perceiver's Processing Experience? Personality and Social Psychology Review. Vol. 8, No. 4, 364-382. https://doi.org/10.1207/s15327957pspr0804_3

Tsikiura, T. and Cabza, R. (2011). Remembering beauty: Roles of Orbitofrontal and hippocampal regions in successful memory encoding of attractive faces, $\quad$ Neurolmage, $\quad 54, \quad 1, \quad 653-660$. https://doi.org/10.1016/j.neuroimage.2010.07.046

Silvia, P.J. (2005). Emotional Responses to Art: From Collation and Arousal Review of General Psychology. Vol. 9, No. 4, 342- $357 . \quad$ https://doi.org/10.1037/10892680.9.4.342

Silvia, P.J. and Brown, E.M. (2007). Anger, Disgust, and the Negative Aesthetic Emotions: Expanding an Appraisal Model of Aesthetic Experience, Psychology of Aesthetics, Creativity, and the Arts. Vol. 1, No. 2, 100-106. https://doi.org/10.1037/1931-3896.1.2.100

Sklar, M. (1999). Student Problem Solving Guide for Use with Complete Business Statistics, Aczel, A., $2^{\text {nd }}$ Edition.

Staricoff, L. (2006). Arts in Health: the Value of Evaluation, Journal of The Royal Society for the Promotion of Health, Vol. 126. No 3, 116-120. https://doi.org/10.1177/1466424006064300

Vartanian, O. and Skov, M. (2014). Neural correlates of viewing paintings: $\quad$ Evidence from a quantitative meta-analysis of functional magnetic imaging data. Brain and Cognition, 87, 52-56. https://doi.org/10.1016/j.bandc.2014.03.004

Vessel, E., Starr, G. and Rubin, N. (2013). Art reaches within: aesthetic experience, the self and the default mode network, Frontier in Neuroscience.

258. https://doi.org/10.3389/fnins.2013.00258

Vikan, G. (2013). "Beauty and Brain Revealed," Dana Foundation, News and Views...,October 29, 2013.

Zaidel, D.W. (2005). Neuropsychology of Art: Neurological. Cognitive and Evolutionary Perspectives. Psychology Press, Hove, UK.

Zeki, S. (1999). Inner Vision: An Exploration of Art and the Brain. Oxford University Press, 1999. 